\title{
The phenomenon of globalisation as the greatest modern megatrend
}

\section{KEYWORDS}

globalization, blurring of boundaries, permeation of cultures, attitude to diversity, autonomy \& dependence, values \& advantages, disadvantages \& risk

\begin{abstract}
The purpose of the article is to present the complexity of the notion of globalisation and the many definitions of this phenomenon. The article presents positions of various authors, including a rich set of variables that determine them. It highlights the importance of blurring boundaries, permeation of cultures, closer relations and multiplicity of interactions on a micro and macro scale. It emphasizes the topic of values and self-awareness of modern human beings in the context of the numerous possibilities and options of choice, as well as its relation to diversity and "Otherness". It attempts to define the aspirations of contemporary human beings by analysing the dichotomy of autonomy and dependence. Globalisation is described as a phenomenon widely developed and still progressing, carrying both opportunities and risks.
\end{abstract}

The history of the process of globalisation goes back several centuries, which makes it rich in threads characteristic of various periods and epochs. The process began to take on particular importance in the mid- $20^{\text {th }}$ century, and the consequence of this development is its present-day description as a megatrend of modernity. Globalisation has become a constant subject of many studies, but in the light of literature on the subject, it is neither an unequivocal concept nor a uniform one. It is also not easy to explain. Some see positive aspects in it, while others perceive it as a threat to the modern world. What connects the insights of all scientists is framing not only the process using its categories, but also the phenomenon which, as A. Cybal-Michalska writes, "can be observed, can be perceived by the senses, [and which] occurs in many areas." In this aspect, the phenomenon of globalisation demands to be identified in more detail, especially in the context of bringing

\footnotetext{
1 A. Cybal-Michalska 2006, p. 16
} 
the changes occurring closer to modern human beings, as well as anticipating the future.

E. Wnuk-Lipiński writes more broadly about globalisation and its processual nature, claiming that "the first step towards globalisation was taken in the $15^{\text {th }}$ and $16^{\text {th }}$ centuries, during the great geographical discoveries. That is when America was discovered, the coast of Africa was charted, and the circum-African route to India was mapped. The first step was taken by brave sailors, but soldiers and missionaries soon followed, along with people we would call politicians and businessmen today." The author suggests that globalisation is not, as is commonly assumed, a completely new phenomenon, but has been progressing for centuries and is currently taking place at a much faster speed. This speed has a significant influence on the quality of the relationship arising as part of this process between individuals, societies and entire nations. E. Wnuk-Lipiński assumes that, despite multiple dependencies, not everything and not everyone has the same chance (ability) to influence each other. "If $[\ldots]$ everything becomes more and more connected with everything else in an arbitrary and symmetrical manner, it is impossible to say anything sensible about this tangle of interdependencies. However, if certain types of events are more connected with each other, and others less, if certain places influence events in other distant locations more strongly, and this relationship is neither arbitrary nor symmetrical, then we can attempt to find the regularities (if not laws) the process is subject to."

This theory appears to be an interesting starting point for analysing the phenomenon of globalisation in the $21^{\text {st }}$ century. It points to the variability and relativity of the surrounding reality, without leaving any doubt as to its constant influence on the functioning of individuals and entire societies. This is confirmed by A. Giddens, who writes that globalisation can be described as "the intensification of worldwide social relations which link distant localities in such a way that local happenings are shaped by events occurring many miles away and vice versa". Elsewhere, he writes: "[...] in a general way, the concept of globalisation is best understood as expressing fundamental aspects of time-space distanciation. Globalisation concerns the intersection of presence and absence, the interlacing of social events and social relations 'at distance' with local contextualities."

Giddens goes on to argue that "One aspect of the dialectical nature of globalisation is the 'push and pull' between tendencies towards centralisation inherent

\footnotetext{
2 E. Wnuk Lipiński 2004, p. 15

${ }^{3}$ E. Wnuk Lipiński 2004, p. 19

4 A. Giddens 2006, p. 47

5 A. Giddens 2006, p. 31
} 
in the reflexivity of the system of states on the one hand and the sovereignty of particular states on the other. Thus, concerted action between countries in some respects diminishes the individual sovereignty of the nations involved, yet by combining their power in other ways, it increases their influence within the state system."' The ambivalence of feelings arising from the above reflections seems to be proof of the yet unresolved consequences of the changes occurring dynamically in the modern world, which are the result of the desire of individual states to maintain their sovereignty, distinctiveness and individuality, and which are at odds with international actions that give a greater sense of agency. In the context of the above considerations, E. Wnuk-Lipiński also addresses important aspects of understanding globalisation by framing it in categories of relativisation, modernisation and homogenisation or hybridisation. According to the author, globalisation manifests as relativisation in the fact of blurring of national boundaries. The migration of people, exchange of goods, services and capital between states takes place increasingly frequently and on an increasing scale. This means that it is necessary to accept and grow familiar with otherness, which until recently appeared quite distant, or was not noticed at all. There is contact with the new, unknown, sometimes even unwanted "Other". What has so far defined the place of an individual in a given society and defined their identity becomes fluid, ambiguous and unsteady. As E. Wnuk-Lipiński writes, "the old 'coordinates' that define out place in society, the set of norms, values and beliefs, which we were inclined to consider as our own, are subject to relativisation, in the sense that although they are still important points of reference for the vast majority, they are no longer absolute. New, supranational coordinates emerge next to them, which are similarly important points of reference for us in everyday life."

Globalisation as modernisation is presented by the author as the process of gradual emergence in human consciousness of the conviction that the reality that surrounds them is only a piece of an enormous global whole. This leads them to perceive new opportunities, new prospects, a new quality of life that other citizens of the world enjoy. This creates an area to take actions and decisions unrelated to current functioning, different from the idea of existence propagated so far. People feel liberated and relieved of their duty to uphold existing traditions. Wnuk-Lipiński writes that "the consequence of this increasingly popular belief is the phenomenon described as 'detraditionalisation,, cal ways of living in favour of ways popularised in the global circulation of goods

\footnotetext{
${ }^{6}$ A. Giddens 2006, p. 53

7 E. Wnuk-Lipinski 2004, p. 24

8 Adam 1996
} 
and services (which stimulate the emergence of new needs), as well as ideas and values which legitimise these new needs." This is also confirmed by A. Giddens, who writes that "every context of detraditionalization creates the possibility of greater freedom of action than in the past." ${ }^{10}$ Finally, globalisation as homogenisation or hybridisation - the process Wnuk-Lipiński calls the rejection of differences by similarities - means the penetration of different societies by identical products and services, which impose specific behaviours, pursuit of specific goals, or paying homage to specific values. Wnuk-Lipiński distinguishes two areas in this process, claiming that "it can be [...] understood as a gradual homogenisation, or the homogenisation of national societies according to a common pattern, but it can also be read as 'hybridisation', or the assimilation of only certain common elements into local cultures." 11 The former understanding of globalisation is related to the domination of one culture over others, as a result of which the latter cease to exist after a time, or their existence does not contribute anything to the overall global cultural system. Hybridisation, on the other hand, means that new elements of the global world penetrate into existing cultures, which transform and assimilate them, and create a new quality together. This is, in a time of progressive globalisation, a variant that gives hope not only for the rise of valuable cultural formations, but also for the preservation of at least part of the achievements of previous generations within existing civilisations.

E. Halizak, reflecting on the direction of the changes in the world, asks whether globalisation is the background for the changes that take place in culture, or whether culture itself is also subject to the process of globalisation. Depending on the answer to this question, the concept of cultural identity may be analysed. It can be either accepted and adopted as a set of specific values and traits, or rejected as an area that defies specification. Observing culture as a field realised within specific structures or social groups, one easily notices that it changes and evolves with the development of certain environments. An example of this is the transformation of language or re-evaluation of accepted norms, ideals, etc. It can therefore be assumed that the process of globalisation affects not so much societies themselves, but the culture within them. It cannot be ruled out that globalisation causes the "over-valuation" of cultures.

According to A. Cybal-Michalska, many researchers and scientists (G. Ritzer, H.P. Martin, H. Schumann), in defining globalisation, look in it for the phenomenon "striving for the creation of a homogenous world and one common socie-

\footnotetext{
${ }^{9}$ E. Wnuk-Lipinski 2004, p. 27

${ }^{10}$ A. Giddens 2000, p. 65

${ }^{11}$ E. Wnuk-Lipinski 2004, p. 28
} 
ty - the global society". ${ }^{12}$ It is thus important to treat globalisation as the aforementioned hybridisation, enriching existing cultures with new values, ideas and models, and strive towards this through joint action on the international arena - actions intended to prevent the vanishing of diverse cultural and social forms in favour of one unified, and consequently pauperised, form of the post-modern world. In the face of such enormous challenges, one may take comfort in $\mathrm{Cy}$ bal-Michalska's assertion that "globalisation favours [...] internationalisation on a global scale more than the totality of universal transformations, taking place in all spheres of social life". ${ }^{13}$ However, does this give hope to the possibility of preserving local diversity and colour despite all the advancing processes of increasing uniformity of the global society? Giddens seems to answer this question partly in the affirmative, analysing the functions and roles of globalisation on the basis of the sociological trend based on interpersonal relations. He describes the clearly emerging dichotomies, stating that " $[\ldots]$ as social relations become laterally stretched and as part of the same process, we see the strengthening of pressures for local autonomy and regional cultural identity." 14 This means that individual societies on the international arena enter into dependencies with others and adapt to global norms in various areas of life in order to achieve equal status. Consequently, they lose the specific character that distinguishes them from the rest of the population. A reaction to the disappearance of characteristic traits, one-ofa-kind and unique in their own way, as well as the frequently growing sense of a loss of exclusivity in decision-making and determining the rules of functioning in a society, is a particular focus on the identity of a given population. Emphasis is placed on preserving cultural distinctiveness, cultivating customs and traditions typical of the region. This frequently involves a sense of being torn between the desire to participate in a global world oriented towards unification, and losses in terms of the unique and singular characteristics of a given society. This has implications for the functioning of specific individuals, who are at the same time citizens of the global world and seemingly separately, citizens of the country in which they live. This internal inconsistency that arises in the minds of individuals often leads to instability in interpersonal relations. On occasion, their cognitive openness and the desire for new experiences comes into conflict with the sense of duty to the need to maintain a cultural and an identity distinctiveness. It is difficult to reconcile the desire to function in the life of global international corporations, which bring together people of various nationalities, creeds and cultures, with the

\footnotetext{
12 A. Cybal-Michalska 2006, p. 2

13 A. Cybal-Michalska, 2006, p. 26

14 A. Giddens 2008, p. 48
} 
desire to maintain a separateness and individuality characteristic of one's country. Demonstration of differences, seen as opposition to the prevailing rules or values, carries the risk of being excluded from a given community. To a certain extent, it becomes necessary to adapt to the existing standards and give up everything that goes beyond the framework adopted in a given environment. There are more similar examples and they also concern the life of individuals within local communities, which are usually focused on what is familiar and "mine". "Otherness", which appears unexpectedly, bringing with it new elements that do not fit the rest of the surroundings, becomes (in the perception of the local population) a threat to the previously cultivated values and customs. Functioning in such a situation is possible only through the creation of certain behaviour schemas intended to reconcile the interests of all parties while at the same time attempting to show trust towards the "other", the "alien". These schemas manifest in various forms and also refer to contacts between individuals of the same collective. They frequently consist of selectively focusing on others. Relations in a society are established through the use of separation and are often very superficial. Deeper dependencies arise only as a result of specific actions aimed at achieving a well-defined goal. Daily relations are characterised by shallowness and briefness. A. Giddens analyses this phenomenon, writing, "The variety of encounters that make up day-to-day life in the anonymous setting of modern social activity are sustained in the first instance by what Goffman has called 'civil inattention"'. ${ }^{15}$ As he adds, "the 'inattention' displayed is not indifference. Rather it I a carefully monitored demonstration of what might be called 'polite estrangement?"' ${ }^{16} \mathrm{E}$. Wnuk-Lipiński points out a similar phenomenon, stating that "the 'global village' is gradually displaced by the 'global city', with social relations characteristic of urban communities (anonymity, low social control, interactions through fragmented social roles rather than through integral personalities, etc.)" ${ }^{17}$ In Goffman's "polite estrangement", ${ }^{18}$ one can look for an attitude that demonstrates a certain trust people have for each other in various situations in life. This attitude helps them to function freely, move about, coexist in a society, it creates a space to be independent and separate. It allows them to maintain distance by at the same time does not close the path to possible mutual contacts and relations. It is therefore a comfortable procedure in an age of widening perspectives, in the face of rapidly progressing changes in the political, economic and cultural spheres.

\footnotetext{
15 A. Giddens 2008, p. 58

16 A. Giddens 2008, p. 58

17 E. Wnuk Lipiński 2004, p. 22

18 E. Goffman 2008
} 
Going further in reflections on the human condition in the era of globalisation, A. Giddens, in his work Modernity and Self-Identity: Self and Society in the Late Modern Age, touches on the notion of identity, inextricably linked with the subject of modernity, also undergoing transformations. He writes: "modernity is a post-traditional order, in which the question 'How shall I live?' has to be answered in day-to-day decisions about how to begave, what to wear and wat to eat - and many other things - as well as interpreted within the temporal unfolding of self-identity" ${ }^{\prime 19}$ This points to the gravity of the situation in which modern humanity finds itself every day, even though they are not always aware of its importance and meaning. Decisions made by every individual influence not only their own life, but also the lives of people around them. On the basis of the domino effect, mistakes can have unpleasant consequences in areas very distant from where the problem arises. This is also true in the case of good choices and positive actions, which are a driving force not only within a given situation, but also far beyond it. A. Giddens frames globalisation in a similar way, writing that it "has to be understood as a dialectical phenomenon, in which events at one pole of a distanciated relation often produce divergent or even contrary occurrences at another". ${ }^{20}$ This phenomenon applies on both the global scale as well as to the lives of individuals, who, making choices and decisions, must be aware of their influence of many areas of not only their own lives, but also those around them. The awareness of these processes and dependencies is particularly important in the era of multiple and varied options of behaviour and a more free ability to make choices than previously. As A. Giddens puts it, "[...] modern social activity has an essentially counterfactual character. In a post-traditional social universe, an indefinite range of potential courses of action (with their attendant risks) is at any given moment open to individuals and collectives." ${ }^{21}$ The risk mentioned by the author should lead to a particularly deep reflection on the circumstances, the state of affairs and the situation in the world, at the same time being a filter in the decision-making process on an individual, social and international scale. But is that the case?

L. Dyczewski also writes that "a citizen of modern society has a sense of freedom, is free to make choices and has the capacity to make them, because modern society offers a vast and diverse palette of goods, services, values, norms, models of living, authorities and events." 22 The individual thus moves through the world, conscious of the fact that there are many options. If one does not bring the ex-

\footnotetext{
19 A. Giddens 2006, p. 21

20 A. Giddens 2006, p. 31

21 A. Giddens 2006, p. 41

22 L. Dyczewski 2009, p. 15
} 
pected results, it can easily be replaced by another. This gives a great sense of security in terms of acting and making decisions, which can become ill-advised and hasty because of this. The postulates of post-modern culture that L. Dyczewski writes about, i.e., "think, calculate, define, negotiate, decide, cancel, start again," ${ }^{23}$ mean that the pursuit of self-fulfilment, so propagated by modern society, sometimes takes on forms dangerous to the individual in the context of their relations with their environment. They become so independent and unfettered that they're actions are actually directed solely towards the realisation of personal happiness. A consequence of this is the deepening problem of interpersonal contacts, which are becoming increasingly shallow, lose meaning and are merely an addition to the whole. Individuals act selfishly without considering the consequences of such conduct. This often translates into commitment to family life, the permanence of relationships, or position and function within social groups. Postmodernists argue that no rules exist and everyone can understand and interpret all religious, national or family symbols in their own way. This axiological relativism makes people stop perceiving the necessity of being guided in life by specific values, since everything is fluid and variable, and it is easier to live without feeling responsible for the actions of oneself or others.

The humanities, as the sciences most focused on human beings, their personality, development and identity, attempt to face the potential and real threats that globalisation of the modern world brings, and to set standards of conduct, pointing to specific values, principles and norms worth of respect, which are rather stable signposts and points of reference. Their intention is primarily to set goals on the basis of social life - within the local, national and international communities, on the internet and in the global dimension. This is a difficult task given the prevailing information chaos and confusion of people in the world, but a necessary one when it comes to the need and desire to influence the shape and image of the world of the future. Lech W. Zacher writes that "in the pessimistic visions of the future, there are usually three elements present: dumbing-down, barbarisation and dehumanisation of human life." ${ }^{4}$

In light of such predictions, we are condemned to live in "a world of aggression and violence, 'urban jungles' full of gangs, crime, drugs, unfriendly schools ruled by violence, unemployment, inequality and misery, a world of mass culture and kitsch, everyday culture that permits primitiveness, rudeness and vulgarity; a world of fast-food in every field, completely commercialised, corrupt and de-

\footnotetext{
23 L. Dyczewski 2009, p. 15

${ }^{24}$ Lech W. Zacher 2003, p. 106
} 
graded; and on the global scale - a world full of hatred, tensions, conflicts, wars [...] and terrorism."25

As A. Cymal-Michalska writes, "by pushing moral doubts that appear in their daily life from their consciousness, the individual condemns themselves to a singular sense of meaninglessness." ${ }^{26}$ This is proof that abandoning analysis and actions aimed at a better future brings an emptiness that cannot be filled with products of the modern world. Their presence in human life has relatively little significance and most likely cannot influence the improvement of the individual's image in the eyes of other people. A person allowing themselves to be ignorant must be aware of the consequences this brings. These consequences are usually rejection, misunderstanding and separation from those who are aware of the need to work together for the benefit of local and global society. As A. Cybal-Michalska continues, "the reflexivity of the individual is connected with uncertainty of tomorrow, risk, existential anxiety, the loss of confidence and security, as well as the need to adopt 'palimpsest identities ${ }^{27}$ - useful in a given moment, in a given situational context, for one-time needs forced on the individual by uncertain reality." ${ }^{28}$ The uncertainty of tomorrow is not a sufficient argument for rejecting the will to cooperate and to search for new values. What is one to do, however, to live in hope that the efforts of modern generations (if undertaken) will yield the expected results and, contrary to what L.W. Zacher writes about, future generations will not be condemned to a life in a world of total lawlessness, corruption and demoralisation? According to Z. Bauman, "The deepest meaning conveyed by the idea of globalisation is that of the indeterminate, unruly and self-propelled character of world affairs; the absence of a center, or a controlling desk, of a board of directors, of a managerial office. Globalisation is Jowitt's 'new world disorder' under another name" and "explicitly refers to von Wright's 'anonymous forces,' operating in the vast - foggy and slushy, impassable and untameable - 'no man's land,' stretching beyond the reach of the design-and-action capacity of anybody's in particular." ${ }^{29}$ Such an approach to the issue sheds light on the success of any social action, desire, intentions or plans.

Bauman writes about "no man's land", which is unexplored, undefined and untameable. It is undeniable that the modern world brings many new elements into the life of each individual. The mass of incoming stimuli and information frequently causes chaos and a sense of confusion. It is also difficult to answer the question

\footnotetext{
${ }^{25}$ Lech W. Zacher 2003, p. 106

26 A. Cybal-Michalska 2006, p. 65-66

27 Z. Bauman 2000

28 A. Cybal-Michalska 2006, p. 66

29 Z. Bauman 2006, p. 71
} 
of values, intentions and principles that rule the present. It is difficult to say what one should be to best function in this present, and consequently, it is also difficult to predict and plan activities that would be aimed at achieving specific goals. In the opinion of those who are not indifferent to the fate of future generations, it is worth trying to describe the existing circumstances in order to be able to take on even the hypothetical assumptions about what might happen in the future. It is difficult to imagine life consisting of an affirmation of the present without deeper reflection about the direction of human aspirations. The automatic and unconscious dwelling in the here and now, without thinking about what awaits the human collective is irresponsible. Such an attitude is not only selfish in its premise, but also leads to the devastation of all goods that humanity has managed to save thus far and a loss of many values that have led to present-day societies being in this place and no other, and demonstrating this potential and no other. Such an attitude also allows for nonchalance and disregard for the shape of the future. It is definitely easier to accept what is offered by a life of diverse options, possibilities and references, a life full of extreme experiences and numerous conveniences, than to knowingly give up full participation in the globalising world for the sake of improving tomorrow. However, it is certain that, as A. Cybal-Michalska writes, citing R. Robertson: "the diversity of responses to globalisation influences the quality, direction and result of this process, which leads to the conclusion that the shape of the 'global field' is significantly dependent on us." ${ }^{30}$ And if that is the case, the appeals of humanists for the need to shape attitudes, to redefine existing patterns of behaviour and to create paradigms in line with the demands of modernity are becoming more understandable. Lech W. Zacher also notes that "the human, social and humanist dimension gets lost somewhere in the triumphant global technological capitalism" 31 and asks relevant questions about values, priorities and the future of humanity in a time of changing reality: "What is mankind today? Where does their evolution lead? What does community or the internet society mean? What is a global information (online) society? And finally, how does one build social capital in the dramatically changing conditions of existing and acting, of setting goals and realising them, in collisions of creativity and adaptability, faced with risky challenges and uncertainties[?]" 32 He tackles the ideas of creativity and adaptability, which are of great importance to modern humans and entire societies, and which frequently become dilemmas in the face of the multiplicity and diversity of available options and the instability of existing points of reference.

\footnotetext{
${ }^{30}$ A. Cybal- Michalska, 2006, p. 20

${ }^{31}$ L. W. Zacher 2003, p. 104

${ }^{32}$ L.W. Zacher 2003, p. 101
} 
Jan Kłos also addresses this issue, asking "how does the self-expressing Self fit into interactions with others, how does it correlate otherness and originality with the demands of social life?"33 The need for consensus between the need for life as an individual and simultaneously as a participant of the ever-growing global community becomes increasingly clear. It may seem that the decision about the degree of belonging and involvement in social life is up to the individual. However, as Professor Ludwig von Mises, a prominent Austrian representative of the liberal movement of the 20th century points out, the importance of the community and the cooperation of people is enormous and sources of happiness should be sought within them. L. Mises attributes all merit in regards to the improving living conditions to cooperation and agreement. According to the author, structures such as democracy are mechanisms that can only work through their rational and proper use. This in turn requires solidarity and genuine interpersonal relations, allowing for unanimous decision-making and concrete action. Therefore, L. Mises emphasises that, "[...] human thoughts and ideas are not the achievement of isolated individuals. Thinking too succeeds only through the cooperation of the thinkers. [...] A man can advance in thinking only because his efforts are aided by those of older generations who have formed the tools of thinking, the concepts and terminologies, and have raised the problems." 34 According to the professor, methodological individualism does not stand in opposition to such entities as nations, states or religious communities, but rather supports them as the agent of action. It is individuals, acting on their own behalf, who at the same time work against the background of the group they co-create. Their aspirations are often very broad and the results of their actions strongly influence the society. As L. Mises emphasises, in order to act effectively, individuals need both spiritual and physical support, but also examples and cooperation.

The rapidly-advancing process of globalisation, even though it still constitutes an object of interest and the subject of scientific observations, resulting in ambivalent emotions and frequently divergent statements about it, has become an undeniable fact. The characteristics of past epochs cannot be ascribed to the 21st century. Its uniqueness, consisting of multiple meanings, significant acceleration of the processes of mutual interpenetration of culture, or the multiplication of potential opportunities in the functioning of individuals means that defining the phenomenon of globalisation in this form seems to be an unrealistic task, sentenced to the constant need of improvement, correction and amendment of the

\footnotetext{
${ }^{33}$ J. Kłos 2007, p. 280

${ }^{34}$ L. von Mises 1966, p. 187-188
} 
formulated meanings. Nevertheless, only by appreciating the writings of the authors mentioned in this article, and the valuable insights of many other scholars of modernity, can one see the enormity and conceptual scope of the phenomenon of globalisation. This in turns creates the opportunity to participate more consciously in a world that, apart from many strengths and values, carries with it risk, uncertainty and a lack of stability.

\section{References}

Bauman Z. Globalizacja, Państwowy Instytut Wydawniczy, Warsaw 20062.

Cybal-Michalska A., Tożsamość młodzieży w perspektywie globalnego świata, Wydawnictwo Naukowe UAM, Poznań 2006.

Dyczewski L., Wyobrażenia młodzieży o małżeństwie i rodzinie, pomiędzy tradycją a nowoczesnością, Wydawnictwo KUL, Lublin 2009.

Giddens A., Konsekwencje nowoczesności, Wydawnictwo Uniwersytetu Jagiellońskiego, Kraków 20085.

Giddens A., Nowoczesność i tożsamość, „Ja” i społeczeństwo w epoce późnej nowoczesności, Wydawnictwo Naukowe PWN, Warsaw 2006.

Kłos J., Wolność, indywidualizm, postęp, Wydawnictwo KUL, Lublin 2007.

Mises L., Human Action: a Treatise on Economics, Contemporary Books, Chicago 1966.

Wnuk-Lipiński E., Świat międzyepoki. Globalizacja. Demokracja. Państwo narodowe, Wydawnictwo Znak, Instytut Studiów Politycznych PAN, Kraków 2004.

Zacher L.W., Spór o globalizację, Eseje o przyszłości świata, Dom Wydawniczy Elipsa, Warsaw 2003. 